\title{
Real-Time Implementation of Starting Current Limitation Method for Cereals Milling Systems Using dSPACE R\&D Controller Board
}

\author{
Moustapha Diop ${ }^{\mathrm{a}, \mathrm{b}, *}$, Samba Gueye ${ }^{\mathrm{b}}$, Oumar Ba ${ }^{\mathrm{b}}$, Lamine Thiaw ${ }^{\mathrm{b}}$ \\ ${ }^{a}$ École Normale Supérieure d'Enseignement Technique et Professionnel, Université Cheikh Anta Diop, Dakar, BP 5004, Sénégal \\ ${ }^{b}$ Laboratoire L3EPI, Ecole Supérieure Polytechnique, Université Cheikh Anta Diop, Dakar, BP 5085, Sénégal \\ Corresponding author: "moustapha17.diop@ucad.edu.sn
}

\begin{abstract}
In this paper, a starting current limitation method of a cereals milling system powered by a photovoltaic micro-grid is proposed. Today, the milling system consisting of a locally designed hammer mill driven by an induction motor is recognized as an innovative and efficient cereal milling solution. For this purpose, they are increasingly being developed in urban and rural areas. Although they offer many advantages, they have some limitations, such as the electromagnetic torque oscillations and the high inrush current at startup. A starting current limitation method based on soft starting technique is proposed to mitigate these negative effects in the transient state. To develop the proposed method, the scalar control principle is used. The scalar control is a simple technique, and it is operated to control the voltage magnitude and the supply frequency. The proposed method has been simulated and compared to conventional direct-on-line starting to evaluate its performance. Simulation results show that the method achieves a predominant performance over the conventional, providing a significant reduction in inrush current while having a lower electromagnetic torque ripple. To validate the method in real-time, an experimental test environment was developed using a dSPACE R\&D 1104 controller board, an induction motor, and a SEMIKRON converter. Real-time experimental results show positive feedback on the proposed current limitation method's efficiency and effectiveness by corroborating the simulation results.
\end{abstract}

Keywords - Cereals milling system; dSPACE R\&D 1104 controller board; induction motor; inrush current; soft starting.

Manuscript received 13 Dec. 2018; revised 27 Jul. 2020; accepted 24 Sep. 2020. Date of publication 30 Apr. 2021. IJASEIT is licensed under a Creative Commons Attribution-Share Alike 4.0 International License.

\section{INTRODUCTION}

In recent years, the cereal milling process is improved rural areas of Senegal. This improvement results from financial support from the Senegalese government and international non-governmental organizations (NGOs). Today, the government and NGOs have recognized the need to embark on development programs for the design and deployment of electric mills in remote villages and rural electrification policies based on the development of solar PV micro-grids. As a result of these development programs, milling systems, like most public applications, are available in rural areas and are powered by micro-grids.

Today, with the availability of these micro-grids, solar mills have become popular and widely used. However, with the increased use of solar mills, more attention has been paid to the design to determine the most appropriate cereal milling systems according to villager specificities. Nowadays, the induction motor-based hammer mill is the most appropriate system in rural areas due to its affordability, simplicity, and robustness [1]-[6].

Traditionally, the milling systems are connected directly to microgrids. With the direct starting, the system starts with full voltage. Therefore, it consumes a high inrush current and produces large torque pulsation [7]-[9]. The adverse effects can affect the system performances and operation of other loads supplied from the common coupling point [10]-[12].

Several starting methods have been developed to reduce these adverse effects [13]-[15]. However, each of the methods has advantages but also limits depending on the application. In this paper, a current limiting method based on the soft starting technique is proposed. The method is based on the scalar control considered a simple technique [16], [17]. Soft starting offers the opportunity to reduce the inrush current by controlling the voltage, as in an induction motor, the current is proportional to the voltage. Thus, with reduced voltage starting, it is possible to reduce the inrush current. On the other hand, with our application, the starting torque 
problem does not arise because the approach keeps the torque constant, and the load does not require a high starting torque.

The proposed method's main advantages are: it is independent of the system parameters, simple and requires only the control of the supply voltage and frequency. The proposed method's effectiveness in suppressing the inrush current is performed by comparing the simulation results with that obtained with the conventional direct-on-line starting process. After that, an experimental test environment was developed using a dSPACE R\&D 1104 controller board, an induction motor, and a SEMIKRON converter to validate the real-time method.

\section{MATERIAL AND METHOD}

\section{A. Description of the system}

Figure 1 shows the global system. It is composed of:

- An AC-to-AC power converter includes an AC/DC converter and a DC/AC converter piloted by a control circuit that generates the switching order for supplying and controlling the system operation.

- A cereal milling system (motor-hammer mill system);

- A control circuit that envelops the control strategies developed for controlling the system operation.

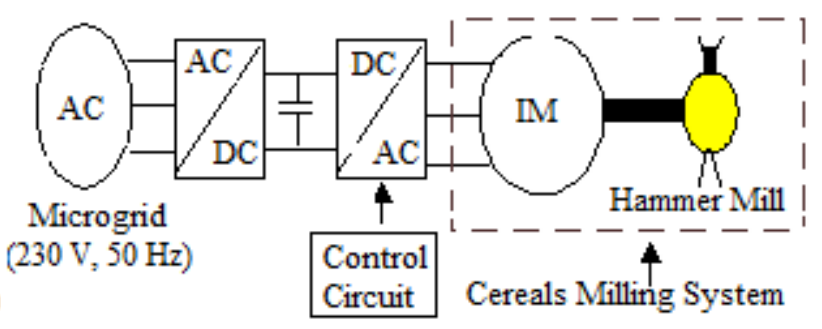

Fig. 1 General block diagram of the proposed system

\section{B. Induction Motor Model}

The equations that govern its operation can be transformed to stationary reference in form complex to model the IM. The electrical equations can be written as [18], [19]:

$$
\begin{gathered}
v_{s}=R_{s} i_{s}+\frac{d \varphi_{s}}{d t}+j \omega_{s} \varphi_{s} \\
v_{r}=R_{r} i_{r}+\frac{d \varphi_{r}}{d t}+j\left(\omega_{s}-\omega_{r}\right) \varphi_{r}
\end{gathered}
$$

The following expressions give the magnetic flux:

$$
\begin{gathered}
\phi_{r}=L_{r} i_{r}+L_{m} i_{s} \\
\varphi_{s}=L_{s} i_{s}+L_{m} i_{r}
\end{gathered}
$$

The electromechanical equation from complex theory is:

$$
J \frac{d \omega_{m}}{d t}=\frac{3}{2} p \frac{L_{m}}{L_{r}} \operatorname{Im}\left[\varphi_{r}^{*} \times i_{s}\right]-T_{l}-f_{r} \omega_{m}
$$

$\mathrm{T}_{1}$ is the mechanical load exerted by the cereals hammer mill. It represents the analytical model of the mill.

\section{Cereals hammer mill (HM) model}

Considering the milling system, the HM is considered as a mechanical load applied to the IM shaft. The HM uses the pulverization technique to mill cereals. When feed millet particles drop into the milling chamber, it is pulverized and reduced under centrifugal forces effect developed by hammers. In [20], the relationship between cereals flow (Q) and load torque exerted by the mill is developed:

$$
T_{l}=\alpha Q^{2}+\beta Q+\gamma
$$

$\alpha, \beta$ and $\gamma$ are characteristic parameters of the cereals mill. It is experimentally determined and given in Table 1 [20]:

TABLE I

Cereals Hammer Mill Parameters

\begin{tabular}{llll}
\hline Parameters & $\boldsymbol{\alpha}$ & $\mathbf{B}$ & $\boldsymbol{\gamma}$ \\
\hline Numerical values & 0.578 & 7.621 & 0.047 \\
\hline
\end{tabular}

\section{Proposed Starting current limitation Method}

From the motor model, the currents vary according to the voltage magnitude. Therefore, a control based on the reduction of voltage and frequency during the starting time may provide the possibility to reduce the inrush current. The proposed method is based on this principle, which is derived from the scalar control technique. Thus, the basic idea is to control the current by keeping the voltage-frequency ratio constant. Based on this scalar control principle, the basic equation of the method is expressed as:

$$
\bar{V}_{s}=R_{s} \bar{I}_{s}+j \omega_{s} \bar{\varphi}_{s}
$$

If the voltage drop $\left(\mathrm{R}_{s} \mathrm{I}_{\mathrm{s}}\right)$ is negligible in comparison to the stator voltage magnitude, the magnetic flux can be expressed directly to the voltage-frequency ratio.

$$
\varphi_{s}=V_{s} / \omega_{s}=V_{s} / 2 \pi f
$$

According to equation (8), the voltage magnitude can be applied gradually as a frequency function during the starting time by maintaining the flux constant. By referring to the proposed method principle, the frequency can be controlled with a linear ramp during this time. However, to elaborate the proposed method, the mill operation's voltage drops and specific characteristics must be considered because a very low-speed operation of the mill can cause damage to the hammer by jamming or an infinite grinding time. To consider both factors, a limit frequency of operation $\left(\mathrm{f}_{0}\right)$ is defined, and the voltage is increased by the threshold value $\left(\mathrm{V}_{0}\right)$ to compensate for the voltage drop. Consequently, the variation of the voltage versus frequency is given by (9). The temporal variation of the frequency is modeled by a linear ramp from zero to the rated value as given in Figure 2.

$$
V_{s}(f)=K \cdot\left(f-f_{0}\right)+V_{0}
$$

The parameter $\mathrm{K}$ is determined given by:

$$
K=\frac{V_{n}-V_{0}}{f_{n}-f_{0}}
$$

Where $f_{n}$ and $V_{n}$ are the rated supply frequency and voltage.

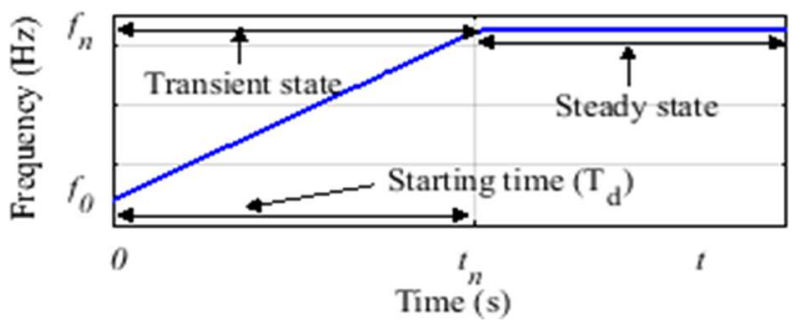

Fig. 2 Temporal variation of the supply frequency 


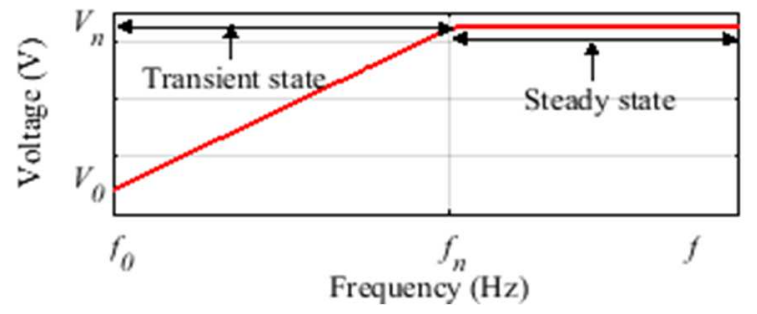

Fig. 3 Stator voltage versus frequency

As shown in Figure 2 and Figure 3, the voltage magnitude versus frequency and the temporal frequency variation are given by the following equations:

$$
\begin{gathered}
V_{s}=\frac{\left(V_{n}-V_{0}\right)}{f_{n}-f_{0}}\left(f-f_{0}\right)+V_{0} \\
f=\frac{f_{n}-f_{0}}{T_{d}} \times t+f_{0}
\end{gathered}
$$

By substituting the frequency equation (11), in the voltage equation (10), the temporal voltage magnitude is:

$$
V_{s}=\frac{\left(V_{n}-V_{0}\right)}{T_{d}} f+V_{0}
$$

\section{RESULTS AND DISCUSSION}

\section{A. Simulation results and discussions}

To investigate the proposed method's effectiveness, two preliminary simulations were performed using the Matlab/Simulink and an induction motor whose specifications are given in Table 1. The first simulation is performed with a fixed starting time of $1.5 \mathrm{~s}$ (Test 1), and the second test (test 2), it is carried out by varying the starting time: $0.25 \mathrm{~s}, 0.50 \mathrm{~s}, 0.75 \mathrm{~s}$ and $1 \mathrm{~s}$. The second test is performed to verify the method's performances according to the applied starting time.

TABLE II

INDUCTION MOTOR SPECIFICATIONS

\begin{tabular}{lllll}
\hline Specifications & Power & Speed & Current & Voltage \\
\hline Values & $750 \mathrm{~W}$ & $2820 \mathrm{rpm}$ & $2.5 \mathrm{~A}$ & $380 \mathrm{~V}$ \\
\hline
\end{tabular}

Figure 4 and 5 show the simulation results of Test 1. A comparison with the conventional starting (DOL) is carried out to evaluate the performance of the proposed starting method through results. Based on the results, the main objective of limiting the inrush current stated above has been achieved. The inrush current peak is $3.3 \mathrm{~A}$, and with the conventional starting, it is $15.04 \mathrm{~A}$. A comparison shows a ratio of about 1.32 concerning the rated current. Whereas with conventional starting, it is six times higher than the rated current.

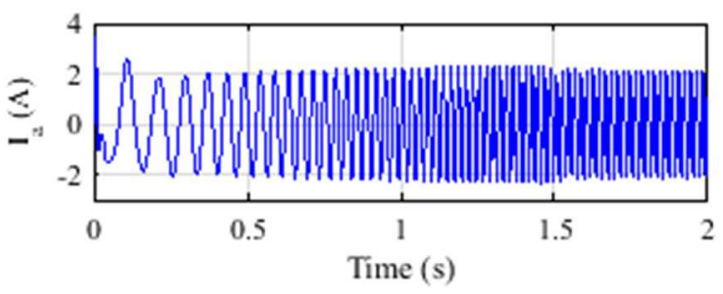

Fig. 4 Inrush current with the proposed method

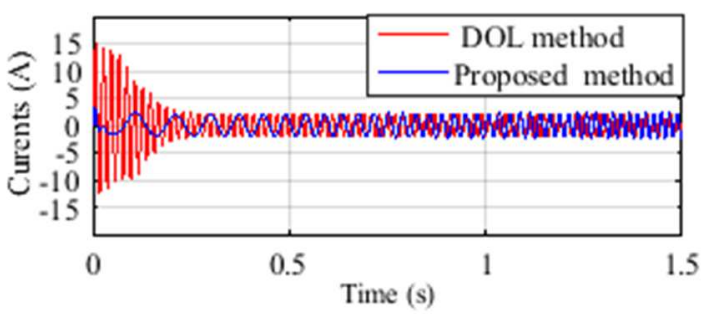

Fig. 5 Current waveforms with DOL and starting approach

Figure 6 show the obtained results with test 2, and Table 2 presents the numerical comparison.
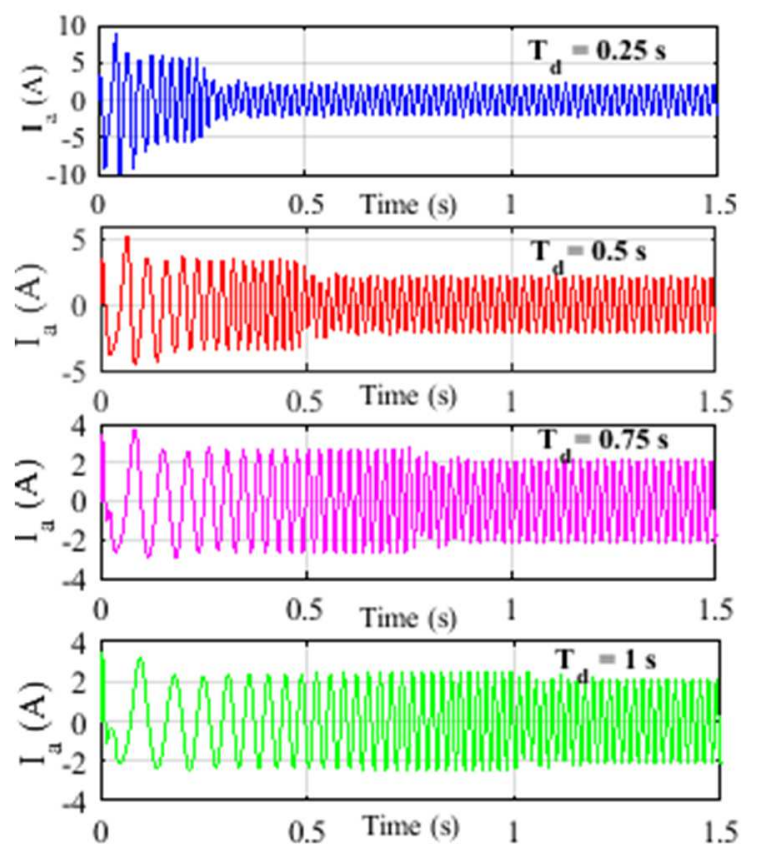

Fig. 6 Inrush current for different starting periods

According to Figure 6, the proposed starting current control, consisting of the linear application of the supply voltage during the starting time, limits the inrush current. Results show that the inrush current is inversely proportional to the starting time (Table 2). This result is explained by the fact that the voltage ramp is slower when the starting time is longer.

TABLE III

NUMERICAL COMPARISON RESULTS

\begin{tabular}{llll}
\hline Starting time (s) & Peak (A) & Ratio & Reduction rate \\
\hline DOL method & 15,04 & 6,02 & 0 \\
0.25 & 8.75 & 3.50 & $41.82 \%$ \\
0.50 & 5.26 & 2.10 & $65.03 \%$ \\
0.75 & 3.67 & 1.47 & $75.60 \%$ \\
1 & 3.40 & 1.36 & $77.39 \%$ \\
1.50 & 3.30 & 1.32 & $78.06 \%$ \\
\hline
\end{tabular}

To verify the system operation with the proposed method, some simulations are carried out by varying the load profile (Figure 7) with a fixed starting time set at 0.75 s. Figures. 8 and 9 show the responses of speeds and electromagnetic torques. 


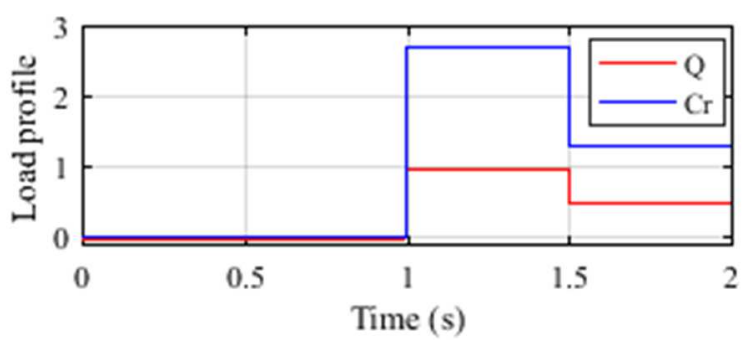

Fig. 7. Typical applied load profile

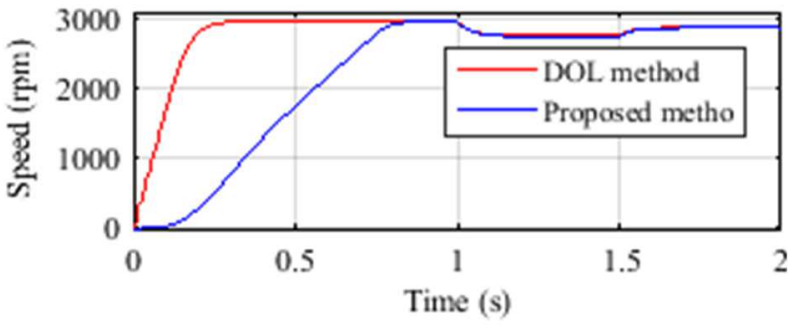

Fig. 8. Shaft rotation speed

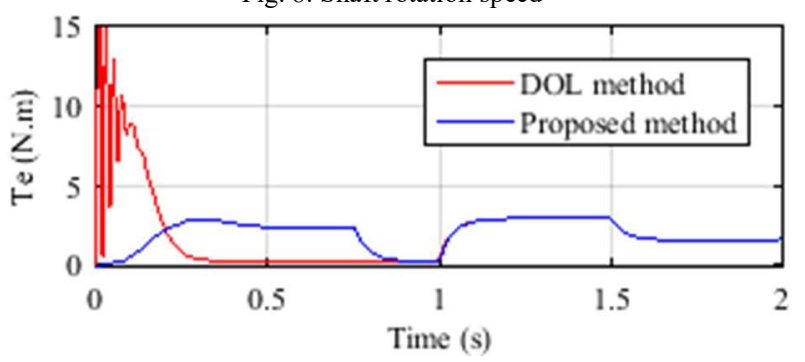

Fig. 9. Electromagnetic torque

The simulation results presented show that the control does not introduce negative effects on the system operation, as shown in the electromagnetic torque and speed variations. With the proposed controller, both torque and speed are admirably adapted to the system's normal operation under different load conditions. However, even a considerable decrease is noted on the torque oscillations, the time of response is longer. It is due to the soft-start approach applied because the response time depends on the applied starting time.

\section{B. Hardware implementation and experimental results}

To investigate in real-time the developed starting method, experimental tests were done. The starting method has been implemented using a test bench installed in Electrical Systems Laboratory of Tunis. The test bench contains:

- A dSPACE DS1104 R\&D controller board:

- A SEMIKRON power converter (20 kVA -30 A).

- A three-phase induction motor coupled to variable mechanical load to model the hammer mill;
- A Personal Computer with Matlab -Simulink software and Control Desk

The Block diagram of the experimental environment consists of the global drive and the experimental test bench. Figure 10 gives the schematic diagram of the experimental test principle, and Figure 11 shows the experimental test bench. Experimental results are obtained to verify the valuable operation of the proposed soft starting.

1) $d S P A C E D S 1104 R \& D$ controller board: The dSPACE consists of a DS1104 board mounted within a PC, a control panel (CP1104) for connecting signal to the DS1104 and software that ensures operating in Simulink. The CP1104 is an input-output interface between the system drive and the DS1104 board [21]-[23]. The DS1104 contains a "Motorola Power PC 603e" model that operates at $250 \mathrm{MHz}$ and a "TMS320F240" DSP controller operating at $20 \mathrm{MHz}$. The DSP has eight 16-bit digital-to-analog converters (DACs) and eight analog-to-digital converters (ADCs). The first four channels of the eight ADCs share a single 16-bit, and the remaining four channels each have a dedicated 12-bit ADC. The DSP controller uses the four 12-bit ADCs to acquire currents and voltage and PWM outputs used to control the converter.

2) A SEMIKRON power converter (20 kVA -30 A): The SEMIKRON converter is an $\mathrm{AC} / \mathrm{DC} / \mathrm{AC}$ converter topology. Its constituted by a bridge three-phase rectifier (400VAC/600V-DC) connected to a three-phase AC supply $(400 / 230 \mathrm{~V}-50 \mathrm{~Hz})$ and the three-phase inverter with a gate drivers circuit SKHI22A 0/15V DC and a brake chopper.

3) Personal Computer (PC) for control: To design, simulate and implement the real-time control of the system, the PC contains Matlab/Simulink and Control Desk software. The control law is designed and built-in Simulink. Parameters in the control law can be tuned from Simulink, and variables can also be traced using Simulink. ControlDesk panel, variables can be displayed or stored, and parameters can be changed.

4) Results: The cereals milling system (motor and load) is driven by the proposed control circuit and fed by a SEMIKRON converter with gate driver circuit SKHI22A. The Matlab script is developed under Simulink, and experimental results are observed with Control Desk. The experimental test operating parameters are chosen as switching frequency $10 \mathrm{kHz}$ and the induction motor parameters using in simulations. For experimentation, the system is fed for a fixed starting period of four seconds $(4 \mathrm{~s})$. Thus, the voltage profile and the line-to-line voltage waveform output are given in Figure 12 and Figure 13, respectively. This method allows sated that supply voltages increase in the transient state to ensure a soft starting. 


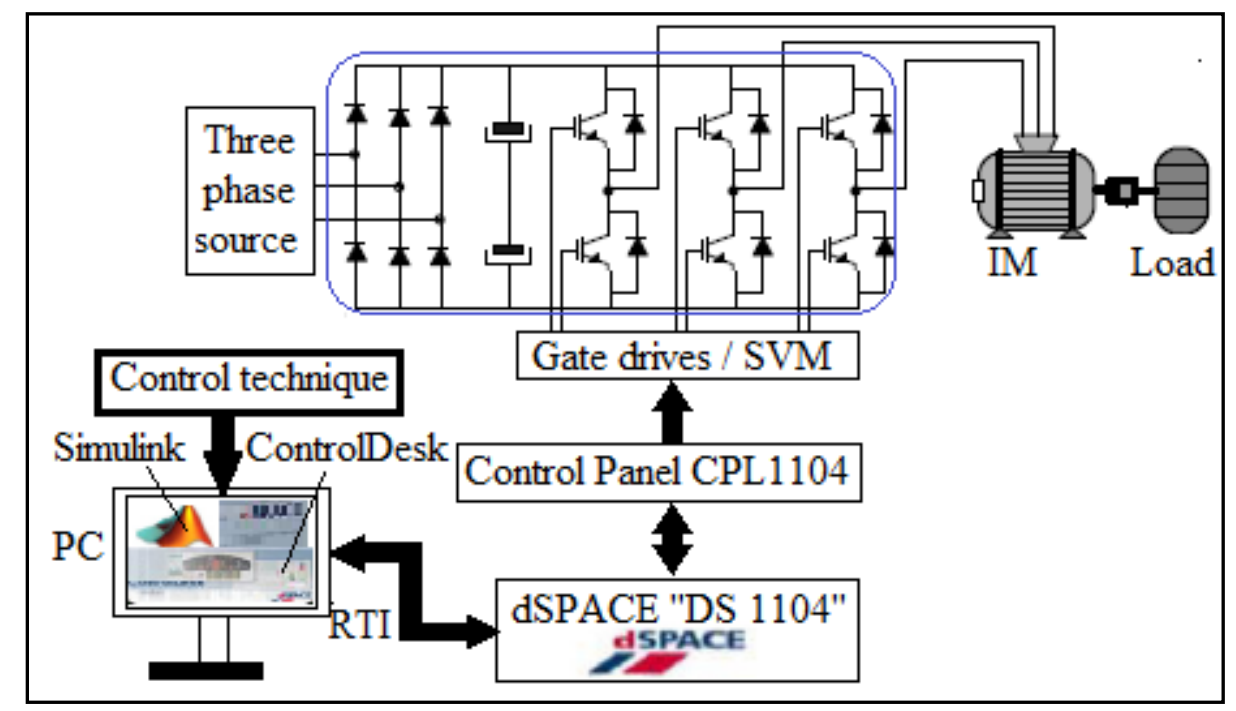

Fig. 10 Schematic diagram of the principle of the experimental test

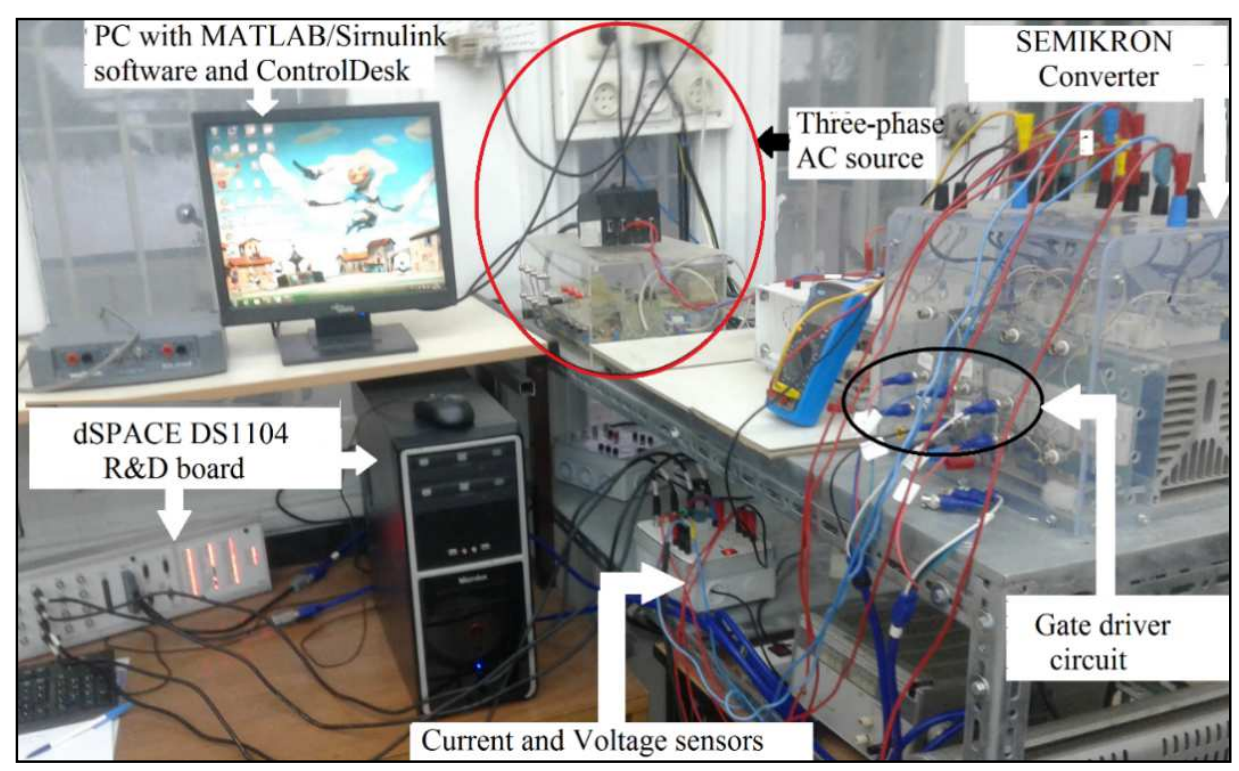

Fig. 11 Experimental test bench

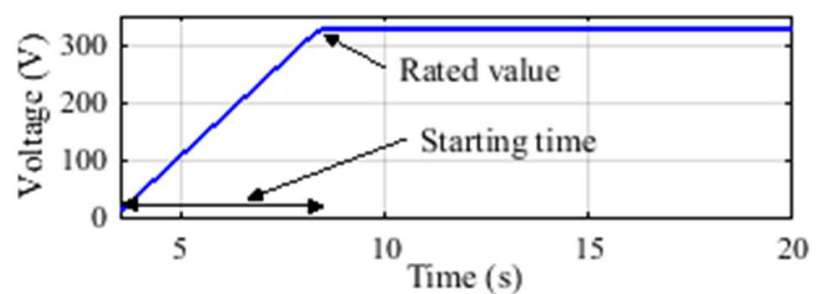

Fig. 12 Experimental applied voltage magnitude profile

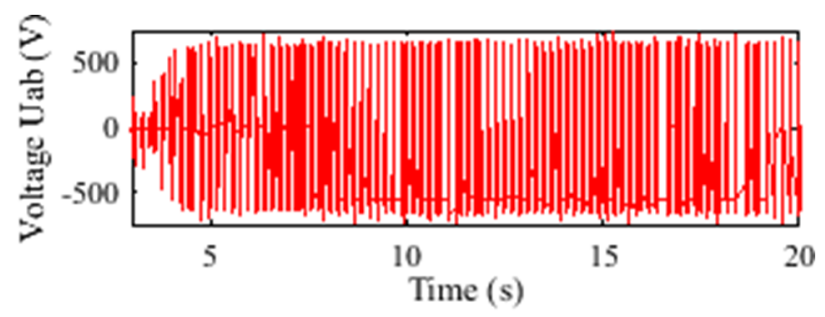

Fig. 13 Output of line to line voltage applied to the motor

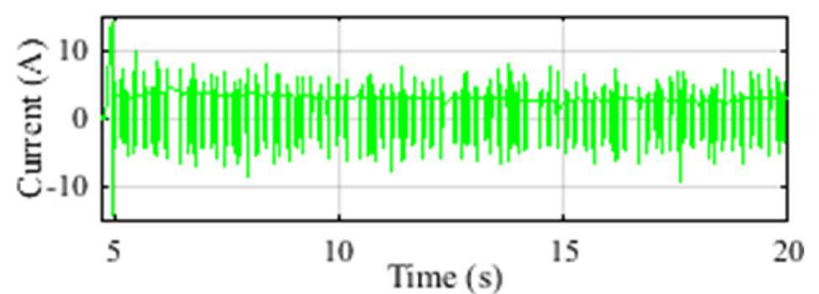

Fig. 14 The current waveform for DOL starting.

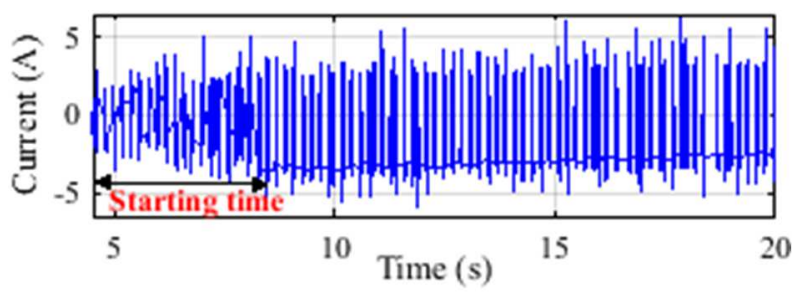

Fig. 15 Measured starting current by applying the method 
Figs. 14 and 15 give the obtained experimental results of the currents using the conventional DOL starting and the proposed starting method. A substantial reducing for the inrush current is noted comparing these obtained experimental results. Thus, the obtained results confirm the results obtained in simulations and. It also ensures the effectiveness of the method of reducing the inrush current. In conclusion, for the strategy proposed in this paper, the starting current and transient torque pulsations can be successfully reduced during the starting period.

\section{CONCLUSION}

In this paper, a control method based on the soft-start technique is proposed to reduce the high inrush current and transient torque pulsations of a milling system consisting of a hammer mill driven by an induction motor. The proposed method is evaluated by simulations and validated in real-time by experimentation using a dSPACE control board. According to simulation results, the current reduction rate varies from $42 \%$ to $78 \%$, depending on the applied starting time. The real-time experimental results show positive feedback on the proposed current limiting method's effectiveness and efficiency by corroborating the simulation results. Overall, the proposed method gives satisfactory results for inrush current limiting with good steady-state stability. However, the method presented is an open-loop control. The next step of this work is to use this method in closed-loop control. It allows to fix the rotation speed and to optimize the energy the efficiency of the grinding system.

\section{NOMENCLATURE}

$\mathrm{L}_{\mathrm{m}}$
$\mathrm{L}_{\mathrm{r}}$
$\mathrm{L}_{\mathrm{s}}$
$\mathrm{R}_{\mathrm{r}}$
$\mathrm{R}_{\mathrm{s}}$
$\omega_{\mathrm{s}}$
$\omega$
$\omega_{\mathrm{m}}$
$\phi_{\mathrm{r}}$
$\phi_{\mathrm{s}}$
$\mathrm{V}_{\mathrm{r}}$
$\mathrm{v}_{\mathrm{s}}$
$\mathrm{i}_{\mathrm{r}}$
$\mathrm{i}_{\mathrm{s}}$
$\mathrm{J}$
$\mathrm{f}_{\mathrm{r}}$
$\mathrm{p}$
$\mathrm{Q}$
$\alpha$
$\beta$
$\mathrm{V}$

mutual inductance

rotor inductance

$\mathrm{H}$

stator inductance

$\mathrm{H}$

rotor resistance

stator resistance

synchronous speed

rotor angular speed

mechanical speed

rotor magnetic flux

rotor magnetic flux

rotor voltage

stator voltage

rotor current

stator voltage

moment of inertia

friction coefficient

number of pole pairs.

cereals flow

cereals milling system parameter

cereals milling system parameter

cereals milling system parameter

$\mathrm{H}$

$\Omega$

$\Omega$

$\operatorname{rad} . \mathrm{s}^{-1}$

$\operatorname{rad} . \mathrm{s}^{-1}$

rad. $\mathrm{s}^{-1}$

$\mathrm{Wb}$

$\mathrm{Wb}$

V

V

A

A

N.m. $\operatorname{rad}^{-1} \cdot s^{2}$

N.m.s.rad ${ }^{-1}$

kg. $\min ^{-1}$

N.m.min ${ }^{2} \mathrm{~kg}^{-2}$

N.m.min. $\mathrm{kg}^{-1}$

N.m

\section{ACKNOWLEDGEMENT}

The experimental results were obtained in the LR 11 ES 15, Electrical Systems Laboratory, National Engineering School of Tunis (ENIT), University of Tunis El Manar, Tunisia and Renewable Energies Laboratory, Polytechnic Higher School, Cheikh Anta Diop University, Senegal

\section{REFERENCES}

[1] A. Pérez-bonilla, M. Frikha, R. P. Lázaro, and G. G. Mateos, "Type of grinding of the main cereal of the diet affects production of brown egglaying hens," vol. 194, pp. 121-130, 2014.

[2] I. Aprodu and I. Banu, "Milling, functional and thermo-mechanical properties of wheat, rye, triticale, barley and oat," J. Cereal Sci., vol. 77, pp. 42-48, 2017.

[3] C. Verucchi, C. Ruschetti, E. Giraldo, G. Bossio, and J. Bossio, "Efficiency optimization in small induction motors using magnetic slot wedges," Electr. Power Syst. Res., vol. 152, pp. 1-8, Nov. 2017.

[4] A. Narendra, N. V. Naik, A. K. Panda, and N. Tiwary, "A Comprehensive Review of PV Driven Electrical Motors," Sol. Energy, vol. 195, no. 2018, pp. 278-303, 2020.

[5] L. Alberto et al., "Performance estimation of three-phase induction motors from no-load startup test without speed acquisition," ISA Trans., vol. 96, pp. 376-389, 2020.

[6] M. B. Payán et al., "Techno-economic optimal power rating of induction motors," Appl. Energy, vol. 240, pp. 1031-1048, 2019.

[7] A. A. M. Faizal and P. Subburaj, "Intelligence Based Soft Starting Scheme for the Three Phase Squirrel Cage Induction Motor with Extinction Angle AC Voltage Controller," Circuits Syst., vol. 7, no. July, pp. 2752-2770, 2016.

[8] M. Jannati et al., "A review on Variable Speed Control techniques for efficient control of Single-Phase Induction Motors: Evolution, classification, comparison," Renew. Sustain. Energy Rev., vol. 75, pp. 1306-1319, 2017.

[9] M. Akbaba, "A novel simple method for elimination of DOL starting transient torque pulsations of three-phase induction motors," Eng. Sci. Technol. an Int. J., no. (In Press, Corrected Proof), 2020.

[10] A. G. Arun Tomar, "Starting Time Calculation for Induction Motor," J. Electr. Electron. Syst., vol. 04, no. 02, pp. 2-5, 2015.

[11] A. Satpute, S. Tambe, V. Shinde, and P. Mone, "Soft starting of three phase induction motor," Int. J. Res. Trends Innov., vol. 2, no. 5, pp. 4 $5,2017$.

[12] J. Chen, J. Li, and R. Qu, “A Restart Strategy of a Rotating Induction Machine for Inrush Current Elimination," IEEE Trans. Ind. Appl. (Early Access ), 2020.

[13] S. Pandey, S. Bahadure, K. Kanakgiri, and N. M. Singh, "Two-phase soft start control of three-phase induction motor," in 2016 IEEE 6th International Conference on Power Systems, 2016.

[14] M. Habyarimana and D. G. Dorrell, "Methods to Reduce the Starting Current of an Induction Motor," 2017 IEEE Int. Conf. Power, Control. Signals Instrum. Eng., pp. 34-38, 2017.

[15] A. Trianni, E. Cagno, and D. Accordini, "Energy efficiency measures in electric motors systems : A novel classification highlighting specific implications in their adoption," Appl. Energy, vol. 252, p. 113481, 2019.

[16] K. Sinan, O. Tolga, and O. Yuksel, "Design and implementation of based asynchronous motor voltage / frequency speed control circuit for the ventilation systems of vehicles," Meas. Control, vol. 52, no. 78, pp. 1039-1047, 2019.

[17] M. E Abid, "Adjustable Speed Drive of Asynchronous Machine Using Volt / Hz \& PI Technique," 2018 IEEE Int. Students' Conf. Electr. Electron. Comput. Sci., pp. 1-5, 2018.

[18] F. Wang, Z. Zhang, X. Mei, J. Rodríguez, and R. Kennel, “Advanced control strategies of induction machine: Field oriented control, direct torque control and model predictive control," Energies, vol. 11, no. 1, pp. 1-13, 2018

[19] A. Hmidet and B. Olfa, "Real-Time Low-Cost Speed Monitoring and Control of Three-Phase Induction Motor via a Voltage/Frequency," Math. Probl. Eng., no. ID 6913813, 2020.

[20] M. Diop, W. Khiari, L. Thiaw, M. Turki, and J. Belhadj, "Characterization and control of a craft mill driven by induction motor fed by photovoltaic mini-grid," Proc. Int. Conf. Recent Adv. Electr. Syst. Tunis., pp. 119-124, 2016.

[21] A. Nouri, I. Salhi, E. Elwarraki, S. El Beid, and N. Essounbouli, "DSPbased implementation of a self-tuning fuzzy controller for three-level boost converter," Electr. Power Syst. Res., vol. 146, pp. 286-297, 2017.

[22] E. Mourabit et al., "Implementation and validation of backstepping control for PMSG wind turbine using dSPACE controller board," Energy Reports, vol. 5, pp. 807-821, 2019.

[23] S. Mensou et al., "Dspace DS1104 Implementation of a Robust Nonlinear Controller Applied for DFIG Driven by Wind Turbine," Renew. Energy, vol. 147, no. Part 1, pp. 1759-1771, 2019. 